\title{
The effect of non-pharmacological sleep interventions on depression symptoms: a meta-analysis of randomised controlled trials
}

Article

Accepted Version

Gee, B., Orchard, F., Clarke, E., Joy, A., Clarke, T. and Reynolds, S. (2019) The effect of non-pharmacological sleep interventions on depression symptoms: a meta-analysis of randomised controlled trials. Sleep Medicine Reviews, 43. pp. 118-128. ISSN 1532-2955 doi:

https://doi.org/10.1016/j.smrv.2018.09.004 Available at https://centaur.reading.ac.uk/79287/

It is advisable to refer to the publisher's version if you intend to cite from the work. See Guidance on citing.

To link to this article DOI: http://dx.doi.org/10.1016/j.smrv.2018.09.004

Publisher: Elsevier

All outputs in CentAUR are protected by Intellectual Property Rights law, including copyright law. Copyright and IPR is retained by the creators or other copyright holders. Terms and conditions for use of this material are defined in the End User Agreement. 


\section{www.reading.ac.uk/centaur}

\section{CentAUR}

Central Archive at the University of Reading

Reading's research outputs online 


\section{The Effect of Non-Pharmacological Sleep Interventions on Depression Symptoms: A}

\section{Meta-Analysis of Randomised Controlled Trials}

Brioney Gee ${ }^{1,2}$, Faith Orchard ${ }^{3}$, Emmet Clarke $^{1}$, Ansu Joy ${ }^{1}$, Tim Clarke ${ }^{1,2}$, Shirley Reynolds ${ }^{3}$

${ }^{1}$ Norfolk and Suffolk NHS Foundation Trust, UK

${ }^{2}$ Norwich Medical School, University of East Anglia, UK

${ }^{3}$ School of Psychology and Clinical Language Sciences, University of Reading, UK

Corresponding Author:

Dr Brioney Gee

Norfolk and Suffolk NHS Foundation Trust

80 St Stephens Road, Norwich, UK. NR1 3RE

Email: brioney.gee@ nsft.nhs.uk Tel: +44 (0)1603 201455

\section{Acknowledgments}

We would like to thank Drs Matthew Blake, Kenneth Lichstein and Ron Postuma for sharing additional data for inclusion in the meta-analysis and the staff of Norfolk and Suffolk NHS Foundation Trust Frank Curtis Library for their assistance in accessing articles. This review was not supported by any specific funding. We have no conflicts of interest to declare. 


\section{Summary}

Poor sleep is a significant risk factor for depression across the lifespan and sleep problems have been hypothesised to contribute to the onset and maintenance of depression symptoms. However, sleep problems are usually not a direct target of interventions for depression. A range of non-pharmacological treatments can reduce sleep problems but it is unclear whether these interventions also reduce other depression symptoms. The aim of this review was to examine whether non-pharmacological interventions for sleep problems are effective in reducing symptoms of depression. We carried out a systematic search for randomised controlled trials of non-pharmacological sleep interventions that measured depression symptoms as an outcome. Forty-nine trials $(\mathrm{n}=5908)$ were included in a random effects metaanalysis. The pooled standardised mean difference for depression symptoms after treatment for sleep problems was -0.45 ( $95 \%$ CI: $-0.55,-0.36)$. The size of the effect on depression symptoms was moderated by the size of the effect on subjective sleep quality. In studies of participants with mental health problems, sleep interventions had a large effect on depression symptoms (d=-0.81, 95\% CI: $-1.13,-0.49)$. The findings indicate that non-pharmacological sleep interventions are effective in reducing the severity of depression, particularly in clinical populations. This suggests that non-pharmacological sleep interventions could be offered as a treatment for depression, potentially improving access to treatment.

\section{Keywords: depression; mood; sleep; insomnia; intervention; treatment; meta-analysis}




\section{Glossary}

Cognitive behavioural therapy for insomnia: A multi-component psychological intervention comprising a range of strategies designed to target the behavioural and cognitive underpinnings of insomnia.

Forest plot: Graphical representation of the results of a meta-analysis.

Funnel plot: Used to detect bias in trials included in a meta-analysis. Publication bias will result in asymmetry in the plot.

Heterogeneity: Variability in observed effect sizes that is greater than would be expected by chance alone.

Meta-regression: A statistical technique that allows the association between continuous, as well as categorical, study characteristics and the intervention effects observed to be investigated.

Paradoxical intention: Instructing the client to stop trying to fall asleep and instead stay awake for as long as possible in order to lessen anxiety about falling asleep.

Rosenthal's failsafe N: The number of additional studies in which the intervention effect was zero that would need to be included in a meta-analysis to increase the P value to above 0.05 .

Sleep restriction therapy: Limiting the time spent in bed to the actual time spent sleeping in order to increase sleep efficiency.

Stimulus control therapy: Providing the client with instructions designed to re-associate the bed/bedroom with sleep. 


\section{Introduction}

Depression is a common mental health problem, with a lifetime prevalence of approximately $15 \%$ in high income countries [1]. It is among the leading causes of disability globally [2], but only a small minority of individuals experiencing depression receive adequate treatment [3]. More than $65 \%$ of adults with major depressive disorder report sleep difficulties [4,5], including difficulty falling asleep, frequent awakenings during the night, early morning awakening and non-restorative sleep [6], and around 40\% report sleep disturbance severe enough to warrant a diagnosis of insomnia [7]. Among adolescents with depression, recent research indicates that up to $90 \%$ present with disturbed sleep [8,9]. In both children and adults, those who experience sleep problems present with more severe depression than depressed individuals without sleep problems $[10,11]$.

Depression has often been conceptualised as a cause of sleep problems [12], reflected in the inclusion of sleep disturbance in the diagnostic criteria for depressive disorders in both commonly used diagnostic manuals (DSM-5 [13] and ICD-10 [14]). However, sleep problems often predate the onset of depression $[15,16]$, and are among the most commonly reported residual symptoms after the remission of a depressive disorder [17]. Thus it has been suggested that, rather than sleep problems being a symptom or consequence of depression, that depression and sleep disorders may constitute separate syndromes that co-occur as a result of shared causal pathways [18].

Longitudinal research suggests a bidirectional relationship between depression and sleep, with sleep disturbances predicting later depressive episodes as well as vice versa [19]. In a 
meta-analysis of longitudinal studies, the risk of non-depressed individuals with insomnia subsequently developing depression was found to be twice that of people without sleep difficulties [20]. Studies examining the prospective role of sleep in the development of depression have found sleep problems to be a risk factor for subsequent depression across the lifespan, from adolescence [21] through to older adulthood [22].

Further, there is some evidence to support the hypothesis that poor sleep might play a causal role in the onset and maintenance of depression symptoms [23,24]. In experimental and quasi-experimental studies, sleep deprivation has been found to increase negative mood [23], decrease positive emotional responses to goal-enhancing events [25] and bring about poorer memory for positively valenced words [26]. In addition, healthy adult volunteers subjected to six days of sleep curtailment have been found to show electroencephalography abnormalities and endocrine disturbances usually observed in depression [18]. In adolescents, even modest sleep restriction over five nights has been found to result in worsened mood, increased irritability and decreased ability to regulate negative emotions [27].

Given the hypothesis that poor sleep might contribute to the onset and maintenance of depression, it is plausible that treatments that are successful in improving sleep might also lead to reductions in symptoms of depression. Pharmacological sleep treatments have been found to produce short-lived improvements in sleep but are not recommended for longer-term sleep problems due to poor efficacy [28] and concerns about dependence and other adverse effects [29]. 
Non-pharmacological interventions are effective in improving sleep, both in individuals with insomnia [30,31], and in those with sleep problems in the context of medical and psychiatric disorders [32-34]. Insomnia is the most common sleep complaint, both in individuals with depression [5,11] and in the general population [34]. A range of non-pharmacological interventions have been found to be effective treatments for insomnia, including stimulus control therapy, relaxation training, sleep restriction therapy, biofeedback, paradoxical intention and multicomponent cognitive behavioural therapy for insomnia (CBT-I) [35].

Depression symptoms are often measured as a secondary outcome in trials of nonpharmacological interventions designed to improve sleep. A number of previous reviews have included analyses of the effect of interventions targeting sleep problems on depression symptoms. The results of previous meta-analyses suggest that both internet-delivered [36] and group-based [37] CBT-I have small but significant effects on depression symptoms, despite these symptoms not being specifically targeted.

However, a recent network meta-analysis of behavioural and cognitive behavioural interventions for adults with insomnia [38] found that only individual, face-to-face CBT-I had a significant effect on depression symptoms when compared to a placebo condition. Studies were included in this analysis if the trial intervention incorporated sleep restriction, and depression was measured using a standardised measure. The authors grouped the CBT-I interventions trialled into six classes according to their treatment components and delivery mode, and compared each class of intervention to placebo conditions (pills or behavioural placebo). Significant moderate-sized mean effects were found for individual CBT-I, but no significant effects were found for other treatment classes. However, the conclusions that 
could be drawn were limited by significant heterogeneity that was not explained by the clinical, demographic or methodological characteristics examined, which included age, sex, whether participants with comorbidities were excluded, and risk of bias.

One possible source of heterogeneity in the effect of sleep interventions on depression is variation in the size of effect on the sleep symptoms directly targeted. The authors of a recent review of CBT-I in adults with co-morbid major depressive disorder [39] suggest that improvement in depression following CBT-I may be mediated by improvement in insomnia symptoms. There are plausible mechanisms through which improvements in sleep might lead to improvements in depression symptoms. These include the impact of improved sleep on quality of life, emotion regulation and cognitive functioning [40,41], as well as reductions in neurobiological abnormalities common to both mood and sleep disturbances [42]. However, there are also a range of non-specific factors that might account for the effect of sleepinterventions on depression, for instance increased motivation or hope as a result of developing a therapeutic relationship or participation in a therapeutic process [43]. As such, the extent to which improvements in depression symptoms are accounted for by improved sleep warrants investigation.

The aim of the current review was to identify and synthesise the results of all randomised controlled trials of non-pharmacological interventions designed to improve sleep that reported depression symptoms as an outcome. Eligible interventions were designed to improve the amount, quality or timing of sleep, including but not limited to interventions for insomnia. The review was not restricted to a particular intervention or client group, and the 
impact of the age of trial participants and presence or absence of mental health comorbidities was examined.

A secondary goal was to examine whether improvements in symptoms of depression were moderated by improvements in subjective sleep quality in order to assess whether heterogeneity in the effect of sleep interventions on depression can be explained by variation in how effective the intervention is in improving perceived sleep quality. Better understanding the impact of non-pharmacological sleep interventions on depression symptoms will be important in enabling us to assess in which cases interventions targeting sleep might be appropriately harnessed as treatment options for depression.

\section{Methods}

\section{Search strategy}

The review was conducted in accordance with guidance in the "preferred reporting items for systematic reviews and meta-analyses' (PRISMA) statement [44]. The protocol was registered with the PROSPERO registry prior to implementation of the search strategy and can be accessed at: http://www.crd.york.ac.uk/PROSPERO/display_record.asp?ID=CRD42017054940.

The search strategy aimed to identify all eligible trials reported in the English language in a peer-reviewed journal. Four electronic databases, PsycINFO, Medline, CINAHL and CENTRAL, were searched from their inception until $1^{\text {st }}$ May 2018. The following search 
terms were used: (sleep OR insomnia OR “sleep treatment” OR "sleep disorders") AND (intervention OR treatment OR therapy OR help OR hygiene OR support OR education) AND (depressi* OR mood). Limiters were used to narrow the search to clinical trials and English language publications. We also hand searched the reference lists of eligible articles and key review papers to identify any eligible articles missed by the electronic search.

\section{Eligibility Criteria}

The inclusion criteria employed were as follows: (1) randomised controlled trial; (2) trial intervention was a non-pharmacological intervention specifically designed to improve sleep (amount, quality or timing); (3) trial included a control condition not designed to improve sleep; (4) depression symptoms were measured (as either a primary or secondary outcome) using a validated instrument; (5) the trial was reported in the English language in a peer reviewed journal. Studies that met any of the following criteria were excluded: (1) the trial intervention included a pharmacological component (including traditional/herbal remedies); (2) all trial arms received an intervention designed to improve sleep (for instance, the only control condition was a pharmacological sleep aid or sleep hygiene); (3) trial intervention was designed to treat parasomnias, sleep apnoea or fatigue (as these are thought to have causal factors distinct from other sleep problems).

\section{Study selection}

The titles and abstracts of all retrieved articles were screened by one reviewer (BG). A subsample of $10 \%$ of articles (selected using a random number generator) was screened independently by a second reviewer (AJ) to check that no potentially eligible articles were 
excluded. The full texts of all articles deemed potentially relevant were obtained and assessed for eligibility against the inclusion/exclusion criteria by two reviewers independently (BG and one of FO, EC, AJ, TC or SR). All disagreements regarding eligibility were discussed by the two reviewers and, if consensus not reached, resolved by a third reviewer. Where multiple publications describing the same trial were identified, only the article reporting on the larger sample was included.

\section{Data extraction and quality assessment}

Data were extracted independently by two reviewers (BG and EC) and cross-checked to ensure accuracy. The following information was recorded using a customised data extraction spreadsheet: study characteristics (authors, title, year of publication), intervention type, age of sample, psychiatric comorbidities, depression measure used, subjective sleep quality measure used, size of intervention and control groups, baseline and outcome data (at first time-point post-intervention) for depression and sleep quality (means and standard deviations). Where insufficient outcome data were reported for the study to be included in the meta-analysis, we contacted corresponding authors to request this data. The methodological quality of included studies was assessed by one reviewer (AJ) using the Cochrane collaboration's risk of bias tool [45]. For a random subsample of $10 \%$ of included studies, the risk of bias assessment was independently verified by a second reviewer (BG) and discrepancies resolved through discussion. 


\section{Data synthesis}

All eligible studies for which sufficient data on depression outcomes were reported or could be obtained from the corresponding author were included in a random effects meta-analysis. Review Manager Version 5.3 [46] was used to perform the meta-analysis. Standardised mean differences of depression scores at post-intervention and their $95 \%$ confidence intervals were calculated for each study, and weighted according to sample size via the random effects model. Standardised mean differences greater than 0.8 were considered large, 0.5 moderate and 0.2 small [47].

Where more than one non-pharmacological intervention designed to improve sleep was included in the trial, data for the most intensive intervention was included in the metaanalysis. The most intensive intervention was determined by consensus of two reviewers based on the amount of face-to-face contact the intervention included (so that interventions delivered in a self-help format were classed as less intensive than therapist-delivered interventions). A random effects model was selected as we expected there would be heterogeneity in study effect sizes because of diversity in their target populations and the specific interventions trialled. Statistical heterogeneity was assessed using the $\mathrm{Chi}^{2}$ and $\mathrm{I}^{2}$ statistics. Significant heterogeneity is indicated by a $\mathrm{Chi}^{2}$ statistic greater than the degrees of freedom and a $\mathrm{p}$ value $<0.05 ; \mathrm{I}^{2}$ values range from $0 \%$ to $100 \%$, with higher values indicating greater heterogeneity [48]. Publication bias was assessed via construction and visual inspection of a funnel plot and by calculating Rosenthal's failsafe N. 
Two planned subgroup analyses were carried out to investigate sources of heterogeneity. The first divided the studies into those that recruited from populations who had sleep problems in the context of mental health problems and those that recruited from populations without clinical mental health problems. Studies were classified as recruiting from a population with mental health problems if all participants either (a) meet standardised diagnostic criteria for at least one functional mental disorder (determined via chart review or diagnostic interview) or (b) scored above the clinical threshold on a validated measure of mental health symptomatology. The second planned subgroup analysis divided the studies according to the age range of participants: children/adolescents (aged up to 19), adults (aged 18+), older adults (aged 50+). Additionally, a post-hoc subgroup analysis was conducted to investigate the impact of the depression measure employed on the effect size detected. Only trials that measured depression using an instrument employed by at least two other trials were included in this analysis.

Finally, a random effects meta-regression was carried out to assess whether the effect of an intervention on depression symptoms was predicted by its effect on subjective sleep quality. This was achieved by calculating effect sizes (standardised mean difference) for all studies that reported subjective sleep quality post-intervention and entering these as covariates in a meta-regression using Field and Gillett's SPSS syntax files [49]. 


\section{Results}

\section{Study selection}

The study selection process is illustrated in Figure 1. Sixty-one papers were identified that met the inclusion criteria, however three were secondary analyses of already included trials and we were unable to obtain sufficient depression data for inclusion in the meta-analysis from the published report or by contacting the corresponding author for nine studies. Therefore data from 49 articles are included in the meta-analysis.

[Inset Figure 1]

\section{Characteristics of included studies}

Characteristics of the 49 trials included in the meta-analysis are summarised in Table 1 . The meta-analysis included data on 5908 participants, of whom 2731 were randomised to receive the trial sleep intervention. The included trials were all of psychological interventions. The majority (39 out of 48 studies) were described by the study authors as CBT-I or CBTinformed interventions. Sixteen studies trialled interventions delivered in a self-help format, online or via a mobile application. The remaining trials were of face-to-face interventions, 27 delivered individually and five delivered in a group format. Control conditions included active interventions not specifically targeting sleep (e.g. dietary advice, exercise programmes), and passive controls, such as medical treatment as usual and waitlist.

Most participants were adults; only four studies included young people aged under 18 $(n=292)$ and none included children under 11 years. Many of the studies recruited participants with physical health problems (e.g. chronic pain, heart failure, cancer), for whom sleep was a secondary or additional problem. Twenty studies recruited participants with sleep problems 
and no other comorbidity. Half of the included studies excluded participants deemed to have clinical levels of depression symptoms (defined either as meeting diagnostic criteria for a depressive disorder or scoring above a specified cut-off on a measure of depression symptoms). A wide range of measures of depression symptoms were used and included widely used self-report questionnaires, as well as observer rating scales (e.g. the Hamilton rating scale for depression). Subjective sleep quality (including self-reported insomnia severity) was measured by 43 of the 49 included studies. The trials were conducted in high and upper-middle income countries across four continents (Europe, North America, Asia and Australasia).

[Insert Table 1]

\section{Risk of bias}

The Cochrane collaboration's risk of bias tool was used to assess the quality of the included studies and a risk of bias summary graph produced (Figure 2). The majority of studies were judged to be of high quality, though few studies were able to blind participants and research personnel, and most papers included insufficient information to be able to determine the risk of bias due to poor allocation concealment or selective reporting. The measures of depression used in the studies had sound psychometric properties, and where young people under 18 were included, had been validated for use with adolescents.

[Insert Figure 2] 


\section{Meta-analysis of effect on depression symptoms at post-treatment}

The results of the random effects meta-analysis are illustrated in Figure 3. There was a small to moderate effect of non-pharmacological sleep interventions in reducing depression symptoms in comparison to control conditions not designed to improve sleep (standardised mean difference $=-0.45,95 \% \mathrm{CI}-0.55,-0.36, \mathrm{p}<0.001, \mathrm{k}=49)$. The statistical heterogeneity in effect sizes among studies was moderate $\left(\mathrm{I}^{2}=56 \%, \chi^{2}=108.8, \mathrm{df}=48, \mathrm{p}<0.001\right)$.

[Inset Figure 3]

\section{Subgroup analyses and meta-regression}

\section{Comorbid mental health difficulties}

Seven of the included studies recruited from participants with clinical mental health problems (typically anxiety, depression and PTSD) in addition to sleep difficulties. The subgroup analyses showed that the pooled effect on depression symptoms for these seven studies was large $($ standardised mean difference $=-0.81,95 \% \mathrm{CI}-1.13,-0.49, \mathrm{p}<0.001, \mathrm{k}=7$ ) and the statistical heterogeneity among these studies was small $\left(\mathrm{I}^{2}=27 \%, \chi^{2}=8.19, \mathrm{df}=6, \mathrm{p}=0.22\right)$. In comparison, the subgroup of studies that recruited participants without clinical mental health difficulties $(\mathrm{k}=42)$ found a small effect on depression symptoms (standardised mean difference $=-0.41,95 \%$ CI $-0.51,-0.31, \mathrm{p}<0.001)$ and these effect sizes were more heterogeneous $\left(\mathrm{I}^{2}=56 \%, \chi^{2}=93.45, \mathrm{df}=41, \mathrm{p}<0.001\right)$. 


\section{Adolescents, adults and older adults}

The majority of included studies recruited adults of all ages. Four of the studies recruited adolescents (all participants under the age of 20) and three recruited only adults over the age of 50. The four trials in adolescents had the smallest pooled effect on depression symptoms (standardised mean difference $=-0.27,95 \% \mathrm{CI}-0.50,-0.04, \mathrm{p}=0.02, \mathrm{k}=4$ ), with no statistical heterogeneity $\left(\mathrm{I}^{2}=0 \%, \chi^{2}=1.99, \mathrm{df}=3, \mathrm{p}=0.57\right)$. The pooled effect on depression symptoms for the studies with adult participants was small to moderate (standardised mean difference $=$ $0.46,95 \% \mathrm{CI}-0.57,-0.36, \mathrm{p}<0.001, \mathrm{k}=42)$ with moderate heterogeneity $\left(\mathrm{I}^{2}=59 \%, \chi^{2}=100.75\right.$, $\mathrm{df}=41, \mathrm{p}<0.001)$. The three studies that recruited adults over the age of 50 had the largest pooled effect size but wide confidence intervals (standardised mean difference $=-0.60,95 \%$ CI $-1.12,-0.08, \mathrm{p}=0.02, \mathrm{k}=3)$ and moderate heterogeneity $\left(\mathrm{I}^{2}=47 \%, \chi^{2}=3.76, \mathrm{df}=2, \mathrm{p}=0.15\right)$.

\section{Depression measure}

The centre for epidemiological studies depression scale (CESD) was the most commonly used depression measure in the included studies $(\mathrm{k}=11)$, followed by the Beck depression inventory (BDI) $(\mathrm{k}=10)$, hospital anxiety and depression scale (HADS) $(\mathrm{k}=8)$, nine item patient health questionnaire (PHQ-9) $(\mathrm{k}=4)$ and the Beck depression inventory version II (BDI-II) (k=3). All other measures were employed in less than three of the included trials. The standardised mean difference was largest for trials that measured depression using the PHQ-9 (-0.70, 95\% CI $-1.00,-0.41, \mathrm{p}<0.001)$, followed by the BDI $(-0.56,95 \%$ CI $-0.76,-$ $0.36, \mathrm{p}<0.001)$, the CESD $(-0.4595 \%$ CIs $-0.67,-0.24, \mathrm{p}<0.001)$, and the HADS $(-0.34,95 \%$ CIs $-0.57,-0.11, p=0.003)$. It was smallest in trials that used the BDI-II $(-0.12,95 \%$ CIs $0.36,0.13, \mathrm{p}=0.34)$. 


\section{Effect on subjective sleep quality}

The standardised mean difference for subjective sleep quality at post-intervention could be calculated in the case of 40 of the 49 included studies. There was a positive linear relationship between the standardised mean difference of the sleep interventions on depression symptoms and the standardised mean difference for subjective sleep quality. The meta-regression revealed that the size of the effect on subjective sleep quality was a significant continuous moderator of the effect on depression symptoms $(\beta=0.447,95 \% \mathrm{CI}$ $0.29,0.60, \mathrm{p}<0.001)$. The residual variation was non-significant $\left(\chi^{2}=41.89, \mathrm{p}=0.306\right)$ suggesting the statistical heterogeneity in the size of the effect of the studied sleep interventions on depression symptoms can be explained by variation in their effect on subjective sleep quality.

\section{Publication bias}

Inspection of the funnel plot suggested that effect sizes might be slightly inflated in some smaller studies, with one small study a notable outlier. However, this might be explained by clinical diversity among the populations studied since trials that recruited participants with sleep problems in the context of mental health problems tended to find larger effect sizes and to have smaller samples than the studies that recruited participants without clinical mental health problems. Rosenthal's failsafe $\mathrm{N}$ was 3593.46, indicating that 3593 studies with zero effect sizes would be needed to nullify the pooled effect. 


\section{Discussion}

We reviewed the evidence of the effect of non-pharmacological interventions designed to improve sleep on the severity of depression symptoms. The meta-analysis showed that nonpharmacological sleep interventions reduce the severity of depression symptoms immediately post-intervention, and this finding was robust to the possibility of publication bias. The pooled effect on depression severity was in the small to moderate range. This is comparable to the effect size of targeted non-pharmacological interventions for depression delivered in primary care [50,51] and to non-pharmacological interventions for depression that is comorbid with physical health problems [52-54]. The effect is, however, somewhat smaller than the effect sizes of non-pharmacological interventions for depression delivered to individuals with major depression disorder [55].

As would be expected given that most eligible trials were of CBT-I, or CBT-informed interventions for insomnia, the effect on depression symptoms we identified is comparable to the effects on depression symptoms reported in previous meta-analyses of CBT-I [36-38]. The size of reduction in depression symptoms is also similar to the effect on anxiety symptoms in a meta-analysis of CBT-I trials [56], suggesting that non-pharmacological sleep interventions are similarly effective in reducing both depression and anxiety.

Whilst the pooled effect of non-pharmacological sleep interventions on depression symptoms is small to moderate, there was considerable heterogeneity in the size of effects observed. This heterogeneity is in line with previous research [38] and unsurprising given the variation in the participants recruited and the type of interventions trialled by the included studies. For 
participants with mental health problems, sleep interventions had a large effect on symptoms of depression. Such interventions have previously been found to have large effects on sleep symptoms in individuals with mental health problems [57]. Therefore, sleep interventions might be of particular benefit to this group.

The pooled effect size for studies that recruited children and adolescents was small compared to the effect sizes for those studies that recruited adults and older adults. These relatively modest effects on depression symptoms are in line with the small effect sizes that have been found in studies of non-pharmacological therapies directly targeting depression in children and young people $[58,59]$. However, none of the studies included in this review investigated the effect of non-pharmacological sleep interventions on children or adolescents with clinical level mental health difficulties, including depression, for whom sleep difficulties are both common and distressing [8,9]. Given the effect of sleep interventions on depression symptoms was larger in studies that recruited participants with sleep problems in the context of mental health problems, the small effect on depression in studies of children and adolescents might be partially accounted for by the lack of trials including young people with clinical-level mental health problems. Therefore, the potential effects of sleep interventions for depressed children and adolescents warrants further evaluation.

There was a strong association between the change in subjective sleep quality brought about by an intervention and its effect on depression symptoms. The statistical heterogeneity in the effect sizes for depression symptoms was nullified by the introduction of the effect size for subjective sleep quality as a covariate in the random effects meta-regression, indicating that the heterogeneity on the effect of the interventions on depression can be explained by 
heterogeneity in their effect on subjective sleep quality. This might support the contention that changes in the severity of depression symptoms were brought about by changes in subjective sleep quality.

However, it is also possible that the observed relationship between effects on depression symptoms and subjective sleep quality is a consequence of non-specific features of the intervention or study context impacting on both sleep and depression symptoms independently. Further research is needed to fully understand the nature of the relationship between the effect of sleep interventions on sleep and their effect on depression. Studies incorporating objective measurement of sleep variables in addition to self-reported sleep quality would potentially be informative.

\section{Clinical implications}

Currently, only a small minority of individuals experiencing depression receive adequate treatment [3]. The stigma associated with mental health problems has been identified as an important barrier to help-seeking and treatment adherence [60]. The effectiveness of nonpharmacological sleep interventions on depression symptoms suggests that the use of nonpharmacological interventions that target sleep (and not mental health difficulties) may offer a relatively low stigma means of reducing depression symptoms in individuals who have both sleep and mental health difficulties. Offering sleep interventions as a treatment option for those who report depression symptoms might also be particularly useful for individuals reluctant to engage in a targeted treatment for depression. 
Non-pharmacological sleep interventions can be successfully delivered in a variety of relatively low-cost formats [28], therefore providing these as a treatment option for people with depression has the potential to be cost-effective. However, caution should be exercised in offering non-pharmacological sleep interventions as a standalone intervention for depression symptoms; residual depression symptoms should be monitored and additional interventions offered as necessary.

\section{Limitations}

A limitation of the current review is that, because diagnostic criteria for depression include sleep problems as a symptom, measures of depression typically incorporate one or more items assessing sleep symptoms. Since these items account for only a small proportion of the total scale score, it is unlikely that changes on these items alone after treatment for sleep problems could account for the size of the effects observed. However, lack of item level data meant that it was not possible to isolate the effect of the interventions trialled on non-sleep depression symptoms. Future trials should use depression measures that do not include items assessing sleep symptoms or report item-level data to enable the effect of sleep interventions on non-sleep depression symptoms to be investigated.

A further consideration in interpreting the results of this meta-analysis is that many studies excluded people who reported elevated symptoms of depression or a history of major depression. Thus, while we cannot be certain what effect this had on the pooled effect size, it is possible that relatively low levels of depression before treatment for sleep problems reduced the overall effect of treatment on depression symptoms. We were also unable to 
assess whether participants in the included trials were offered treatment for depression or provided with mood management techniques before or after their participation in the sleep interventions trialled as this was not consistently reported.

The meta-analysis only included trials that reported adequate data on depression symptoms at post-treatment. We could not include nine trials identified as eligible for inclusion in the meta-analysis as we were unable to obtain sufficient data on depression outcome to calculate the standardised mean difference. Also, we focused on outcomes immediately postintervention so are unable to comment on the longevity of the effects on depression observed. Further, we only included trials that measured depression symptoms as an outcome. It is possible that trials of non-pharmacological sleep interventions that did not measure depression symptoms as an outcome might have differed from those that did in some fashion that would impact the size of the effect obtained.

\section{Conclusions}

Non-pharmacological interventions designed to improve sleep have a positive impact on depression symptoms. The size of the effect on depression is moderated by the effect on subjective sleep quality and is largest for participants experiencing sleep problems in the context of mental health difficulties. Further research investigating the mechanisms by which sleep interventions impact depression symptoms is warranted. 


\section{Practice points}

1. Available randomised controlled trial evidence indicates that non-pharmacological interventions designed to improve sleep have a small to moderate effect on depression symptoms when these are measured as a secondary outcome.

2. The size of the effect on depression symptoms is moderated by the effect of the intervention on subjective sleep quality.

3. The effect on depression symptoms appears to be larger in adult than in children and adolescents but this may be an artefact of the participants who were recruited.

4. We found evidence of a large effect for studies that recruited participants experiencing sleep problems in the context of mental health difficulties. Offering nonpharmacological sleep interventions to users of mental health services who are experiencing concomitant mood and sleep problems may lead to significant improvements in depression symptoms as well as sleep quality.

\section{Research agenda}

1. Future trials of sleep interventions should measure depression symptoms as an outcome and report this data at item level where the depression instrument used includes an item(s) assessing sleep problems.

2. Future studies should investigate the mechanisms through which sleep interventions lead to improvements in depression symptoms.

3. The effect of sleep interventions on depression in children and adolescents with mental health problems should be trialled. 


\section{References}

[1] Kessler RC, Bromet E. The epidemiology of depression across cultures. Annu Rev Public Health 2013;34:119-38. doi:10.1146/annurev-publhealth-031912-114409. The.

[2] World Health Organisation. The Global Burden of Disease: 2004 update. 2008. doi:10.1038/npp.2011.85.

[3] Thornicroft G, Chatterji S, Evans-Lacko S, Gruber M, Sampson N, Aguilar-Gaxiola S, et al. Undertreatment of people with major depressive disorder in 21 countries. Br J Psychiatry 2017;210:119-24. doi:10.1192/bjp.bp.116.188078.

[4] Yates WR, Mitchell J, Rush AJ, Trivedi MH, Wisniewski SR, Warden D, et al. Clinical features of depressed outpatients with and without co-occurring general medical conditions in STAR*D. Gen Hosp Psychiatry 2004;26:421-9. doi:10.1016/j.genhosppsych.2004.06.008.

[5] Perlis ML, Giles DE, Buysse DJ, Thase ME, Tu X, Kupfer DJ. Which Depressive Symptoms Are Related to Which Sleep Electroencephalographic Variables? Biol Psychiatry 1997;42:904-13.

[6] *Benca RM, Peterson MJ. Insomnia and depression. Sleep Med 2008;9:3-9. doi:10.1016/S1389-9457(08)70010-8.

[7] Stewart, Besset, Bebbington, Burgha, Lindesay, Jenkins, et al. Insomnia Comorbidity and Impact and Hypotic Use by Age Group in a National Survey Population Aged 16 to 74 Years. Sleep 2006;29:1391-7.

[8] *Orchard F, Pass L, Marshall T, Reynolds S. Clinical characteristics of adolescents referred for treatment of depressive disorders. Child Adolesc Ment Health 2017;22:618. doi:10.1111/camh.12178.

[9] Goodyer IM, Reynolds S, Barrett B, Byford S, Dubicka B, Hill J, et al. Cognitivebehavioural therapy and short-term psychoanalytic psychotherapy versus brief psychosocial intervention in adolescents with unipolar major depression (IMPACT): A multicentre, pragmatic, observer-blind, randomised controlled trial. Health Technol Assess (Rockv) 2017;21:1-93. doi:10.3310/hta21120.

[10] Soehner A, Kaplan K, Harvey AG. Prevalence and clinical correlates of co-occuring insomnia and hypersomnia symptoms in depression. J Affect Disord 2014;167:93-7.

[11] Liu X, Buysse DJ, Gentzler AL, Kiss E, Mayer L, Kapornai K, et al. Insomnia and hypersomnia associated with depressive phenomenology and comorbidity in childhood depression. Sleep 2007;30:83-90. doi:10.1093/sleep/30.1.83.

[12] Riemann D. Insomnia and comorbid psychiatric disorders. Sleep Med 2007;8:15-20. doi:10.1016/j.sleep.2007.04.011.

[13] American Psychiatric Association. Diagnostic and statistical manual of mental disorders. 5th Edition. American Psychiatric Association; 2013.

[14] World Health Organisation. The ICD-10 Classification of Mental and Behavioural Disorders: Clinical descriptions and diagnostic guidelines 1992. 
[15] Breslau N, Roth T, Rosenthal L, Andreski P. Sleep disturbance and psychiatric disorders: A longitudinal epidemiological study of young adults. Biol Psychiatry 1996;39:411-8. doi:10.1016/0006-3223(95)00188-3.

[16] Roberts RE, Duong HT. Depression and insomnia among adolescents: A prospective perspective. J Affect Disord 2013;148:66-71. doi:10.1016/j.jad.2012.11.049.

[17] Carney C, Segal Z, Edinger J, Krystal A. A comparison of rates of residual insomnia symptoms following pharmacotherapy or cognitive-behavioral therapy for major depressive disorder. J Clin Psychiatry 2007;68:254-60.

[18] Staner L. Comorbidity of insomnia and depression. Sleep Med Rev 2010;14:35-46. doi:10.1016/j.smrv.2009.09.003.

[19] *Alvaro PK, Roberts RM, Harris JK. A Systematic Review Assessing Bidirectionality between Sleep Disturbances, Anxiety, and Depression. Sleep 2013;36:1059-68. doi:10.5665/sleep. 2810 .

[20] *Baglioni C, Battagliese G, Feige B, Spiegelhalder K, Nissen C, Voderholzer U, et al. Insomnia as a predictor of depression: A meta-analytic evaluation of longitudinal epidemiological studies. J Affect Disord 2011;135:10-9.

doi:10.1016/j.jad.2011.01.011.

[21] Lovato N, Gradisar M. A meta-analysis and model of the relationship between sleep and depression in adolescents: Recommendations for future research and clinical practice. Sleep Med Rev 2014;18:521-9. doi:10.1016/j.smrv.2014.03.006.

[22] Franzen PL, Buysse DJ. Sleep disturbances and depression: Risk relationships for subsequent depression and therapeutic implications. Dialogues Clin Neurosci 2008; 10:473-81.

[23] Harvey AG, Murray G, Chandler RA, Soehner A. Sleep Disturbance as Transdiagnostic: Consideration of Neurobiological Mechanisms. Clin Psycohology Rev 2012;31:225-35. doi:10.1016/j.cpr.2010.04.003.Sleep.

[24] Dolsen MR, Asarnow LD, Harvey AG. Insomnia as a transdiagnostic process in psychiatric disorders. Curr Psychiatry Rep 2014;16:471. doi:10.1007/s11920-0140471-y.

[25] Zohar D, Tzischinsky O, Epstein R, Lavie P. The Effects Events of Sleep Loss a Cognitive-Energy on Medical Model Residents' Emotional Reactions to Work. Sleep 2005;28:47-54. doi:10.1093/sleep/28.1.47.

[26] Walker MP, Stickgold R. Sleep, Memory, and Plasticity. Annu Rev Psychol 2006;57:139-66. doi:10.1146/annurev.psych.56.091103.070307.

[27] Baum KT, Desai A, Field J, Miller LE, Rausch J, Beebe DW. Sleep restriction worsens mood and emotion regulation in adolescents. J Child Psychol Psychiatry 2014;55:180 90. doi:10.1111/jcpp.12125.Sleep.

[28] Espie CA. "Stepped Care": A Health Technology Solution for Delivering Cognitive Behavioral Therapy as a First Line Insomnia Treatment. Sleep 2009;32:1549-58.

[29] National Institute for Health and Care Excellence. Guidance on the use of zaleplon, 
zolpidem and zopiclone for the short-term management of insomnia. 2004.

[30] Edinger JD, Means MK. Cognitive-behavioral therapy for primary insomnia. Clin Psychol Rev 2005;25:539-58. doi:https://doi.org/10.1016/j.cpr.2005.04.003.

[31] Morin CM, Bootzin RR, Buysse DJ, Edinger JD, Espie CA, Lichstein KL. Psychological And Behavioral Treatment Of Insomnia: Update Of The Recent Evidence (1998-2004). Sleep 2006;29:1398-414. doi:10.1093/sleep/29.11.1398.

[32] Riemann D, Perlis ML. The treatments of chronic insomnia: A review of benzodiazepine receptor agonists and psychological and behavioral therapies. Sleep Med Rev 2009;13:205-14. doi:10.1016/j.smrv.2008.06.001.

[33] Smith MT, Huang MI, Manber R. Cognitive behavior therapy for chronic insomnia occurring within the context of medical and psychiatric disorders. Clin Psychol Rev 2005;25:559-92.

[34] *Geiger-Brown JM, Rogers VE, Liu W, Ludeman EM, Downton KD. Cognitive behavioral therapy in persons with comorbid insomnia : A meta-analysis. Sleep Med Rev 2015;23:54-67. doi:10.1016/j.smrv.2014.11.007.

[35] Morgenthaler T, Kramer M, Friedman L, Boehlecke B, Brown T, Coleman J, et al. Practice parameters for the psychological and behavioral treatment of insomnia: an update. An american academy of sleep medicine report. Sleep 2006;29:1415-9.

[36] *Ye Y, Zhang Y, Chen J, Liu J, Li X, Liu Y, et al. Internet-Based Cognitive Behavioral Therapy for Insomnia (ICBT-i) Improves Comorbid Anxiety and Depression-A Meta-Analysis of Randomized Controlled Trials. PLoS One 2015;10:e0142258. doi:10.1371/journal.pone.0142258.

[37] *Koffel EA, Koffel JB, Gehrman PR. A meta-analysis of group cognitive behavioral therapy for insomnia. Sleep Med Rev 2015;19:6-16. doi:10.1016/j.smrv.2014.05.001.

[38] *Ballesio A, Aquino MRJ V., Feige B, Johann AF, Kyle SD, Spiegelhalder K, et al. The effectiveness of behavioural and cognitive behavioural therapies for insomnia on depressive and fatigue symptoms: A systematic review and network meta-analysis. Sleep Med Rev 2018;37:114-29. doi:10.1016/j.smrv.2017.01.006.

[39] *Cunningham JEA, Shapiro CM. Cognitive Behavioural Therapy for Insomnia (CBTI) to treat depression: A systematic review. J Psychosom Res 2018;106:1-12. doi:10.1016/j.jpsychores.2017.12.012.

[40] Harvey G. Insomnia, Psychiatric Disorders and the Transdiagnostic Disorders Perspective. Assoc Psychol Sci 2008;17:299-303. doi:doi: 10.1111/j.14678721.2008.00594.x.

[41] Palmer CA, Alfano CA. Sleep and emotion regulation: An organizing, integrative review. Sleep Med Rev 2017;31:6-16. doi:10.1016/j.smrv.2015.12.006.

[42] Kahn M, Sheppes G, Sadeh A. Sleep and emotions: Bidirectional links and underlying mechanisms. Int J Psychophysiol 2013;89:218-28.

doi:10.1016/j.ijpsycho.2013.05.010.

[43] Mulder R, Murray G, Rucklidge J. Common versus specific factors in psychotherapy: 
opening the black box. The Lancet Psychiatry 2017;4:953-62. doi:10.1016/S22150366(17)30100-1.

[44] Moher D, Liberati A, Tetzlaff J, Altman DG, Altman D, Antes G, et al. Preferred reporting items for systematic reviews and meta-analyses: The PRISMA statement. PLoS Med 2009;6:e1000097. doi:10.1371/journal.pmed.1000097.

[45] Higgins J, Green S. Cochrane handbook for systematic reviews of interventions. Chichester: JohnWiley \& Sons, Ltd; 2008.

[46] The Cochrane Collaboration. Review Manager (RevMan) 2014.

[47] Cohen J. Statistical Power Analysis for the Behavioral Sciences. New York: Routledge; 1988.

[48] Ryan R. Heterogeneity and subgroup analyses in Cochrane Consumers and Communication Review Group reviews: Planning the analysis at protocol stage 2016. http://cccrg.cochrane.org.

[49] Field AP, Gillett R. How to do a meta-analysis. Br J Math Stat Psychol 2010;63:66594. doi:10.1348/000711010X502733.

[50] Cuijpers P, Straten A Van, Schaik A Van, Andersson G. Psychological treatment of depression in primary care: a meta-analysis. Br J Gen Pract 2009:e51-60. doi:10.3399/bjgp09X395139.

[51] Twomey C, Byrne M. Effectiveness of cognitive behavioural therapy for anxiety and depression in primary care: a meta-analysis. Fam Pract 2017;32:3-15. doi:10.1093/fampra/cmu060.

[52] Fiest KM, Walker JR, Bernstein CN, Graff LA, Zarychanski R, Abou-Setta AM, et al. Systematic review and meta-analysis of interventions for depression and anxiety in persons with multiple sclerosis. Mult Scler Relat Disord 2016;5:12-26. doi:10.1016/j.msard.2015.10.004.

[53] van der Feltz-Cornelis CM, Nuyen J, Stoop C, Chan J, Jacobson AM, Katon W, et al. Effect of interventions for major depressive disorder and significant depressive symptoms in patients with diabetes mellitus: A systematic review and meta-analysis. Gen Hosp Psychiatry 2010;32:380-95. doi:10.1016/j.genhosppsych.2010.03.011.

[54] Sheard T, Maguire P. The effect of psychological interventions on anxiety and depression in cancer patients: Results of two meta-analyses. Br J Cancer 1999;80:1770-80. doi:10.1038/sj.bjc.6690596.

[55] Cuijpers P, Andersson G, Donker T, van Straten A. Psychological treatment of depression: Results of a series of meta-analyses. Nord J Psychiatry 2011;65:354-64. doi:10.3109/08039488.2011.596570.

[56] Belleville G, Cousineau H, Levrier K, St-Pierre-Delorme ME. Meta-analytic review of the impact of cognitive-behavior therapy for insomnia on concomitant anxiety. Clin Psychol Rev 2011;31:638-52. doi:10.1016/j.cpr.2011.02.004.

[57] *Taylor DJ, Pruiksma KE. Cognitive and behavioural therapy for insomnia (CBT-I) in psychiatric populations: A systematic review. Int Rev Psychiatry 2014;26:205-13. 
doi:10.3109/09540261.2014.902808.

[58] Weisz JR, Kuppens S, Ng MY, Eckshtain D, Ugueto AM, Vaughn-Coaxum R, et al. What five decades of research tells us about the effects of youth psychological therapy: A multilevel meta-analysis and implications for science and practice. Am Psychol 2017;72:79-117. doi:10.1037/a0040360.

[59] Weisz JR, McCarty CA, Valeri SM. Effects of psychotherapy for depression in children and adolescents: A meta-analysis. Psychol Bull 2006;132:132-49. doi:10.1037/0033-2909.132.1.132.

[60] Clement S, Schauman O, Graham T, Maggioni F, Evans-Lacko S, Bezborodovs N, et al. What is the impact of mental health-related stigma on help-seeking? A systematic review of quantitative and qualitative studies. Psychol Med 2015;45:11-27. doi:10.1017/S0033291714000129.

[61] Blake M, Waloszek JM, Schwartz O, Raniti M, Simmons JG, Blake L, et al. The SENSE Study : Post Intervention Effects of a Randomized Controlled Trial of a Cognitive - Behavioral and Mindfulness-Based Group Sleep Improvement Intervention Among At-Risk Adolescents. J Consult Clin Psychol 2016;84:1039-51.

[62] Casault L, Savard J, Ivers H, Savard MH. A randomized-controlled trial of an early minimal cognitive-behavioural therapy for insomnia comorbid with cancer. Behav Res Ther 2015;67:45-54. doi:10.1016/j.brat.2015.02.003.

[63] Chang YL, Chiou AF, Cheng SM, Lin KC. Tailored educational supportive care programme on sleep quality and psychological distress in patients with heart failure: A randomised controlled trial. Int J Nurs Stud 2016;61:219-29.

doi:10.1016/j.ijnurstu.2016.07.002.

[64] Christensen H, Batterham PJ, Gosling JA, Ritterband LM, Griffiths KM, Thorndike FP, et al. Effectiveness of an online insomnia program (SHUTi) for prevention of depressive episodes (the GoodNight Study): A randomised controlled trial. The Lancet Psychiatry 2016;3:333-41. doi:10.1016/S2215-0366(15)00536-2.

[65] Currie SR, Wilson KG, Pontefract AJ, DeLaplante L. Cognitive-behavioural treatment of insomnia secondary to chronic pain. Int J Nurs Stud 2000;68:407-16.

[66] Currie SR, Clark S, Hodgins DC, El-Guebaly N. Randomized controlled trial of brief cognitive-behavioural interventions for insomnia in recovering alcoholics. Addiction 2004;99:1121-32. doi:10.1111/j.1360-0443.2004.00835.x.

[67] Dewald-Kaufmann JF, Oort FJ, Meijer AM. The effects of sleep extension and sleep hygiene advice on sleep and depressive symptoms in adolescents: A randomized controlled trial. J Child Psychol Psychiatry Allied Discip 2014;55:273-83. doi:10.1111/jcpp.12157.

[68] Ebert DD, Thiart H, Laferton JAC, Berking M, Riper H, Cuijpers P, et al. Restoring depleted resources: Efficacy and mechanisms of change of an internet-based unguided recovery training for better sleep and psychological detachment from work. Heal Psychol 2015;34:1240-51. doi:10.1037/hea0000277.

[69] Edinger JD, Wohlgemuth WK, Radtke RA, Marsh G, Quillian RE. Cognitive 
Behavioral Therapy for Treatment of Chronic Insomnia: A Randomized Controlled Trial. JAMA 2001;283:1856-64.

[70] Edinger JD, Wohlgemuth WK, Radtke RA, Coffman CJ, Carney CE. Dose-response effects of cognitive-behavioral insomnia therapy: A randomized clinical trial. Sleep 2007;30:203-12. doi:10.1093/sleep/30.2.203.

[71] Freeman D, Sheaves B, Goodwin GM, Yu L, Nickless A, Harrison PJ, et al. The effects of improving sleep on mental health (OASIS): a randomised controlled trial with mediation analysis. The Lancet Psychiatry 2017;4:749-58. doi:10.1016/S22150366(17)30328-0.

[72] Galovski TE, Blain LM, Elwood L, Gloth C, Fletcher TD, Harik JM. Augmenting Cognitive Processing Therapy to Improve Sleep Impairment in PTSD: A Randomized Controlled Trial. J Consult Cinical Psychol 2016;84:167-77. doi:10.1037/ccp0000059.Augmenting.

[73] Gradisar M, Dohnt H, Gardner G, Paine S, Starkey K, Menne A, et al. A randomized controlled trial of cognitive-behavior therapy plus bright light therapy for adolescent delayed sleep phase disorder. Sleep 2011;34:1671-80.

doi:http://dx.doi.org/10.5665/sleep.1432.

[74] Ho FYY, Chung KF, Yeung WF, Ng THY, Cheng SKW. Weekly brief phone support in self-help cognitive behavioral therapy for insomnia disorder: Relevance to adherence and efficacy. Behav Res Ther 2014;63:147-56. doi:10.1016/j.brat.2014.10.002.

[75] Horsch CH, Lancee J, Griffioen-Both F, Spruit S, Fitrianie S, Neerincx MA, et al. Mobile Phone-Delivered Cognitive Behavioral Therapy for Insomnia: A Randomized Waitlist Controlled Trial. J Med Internet Res 2017;19:e70.

[76] Hou Y, Hu P, Liang Y, Mo Z. Effects of Cognitive Behavioral Therapy on Insomnia of Maintenance Hemodialysis Patients. Cell Biochem Biophys 2014;69:531-7. doi:10.1007/s12013-014-9828-4.

[77] Irwin MR, Olmstead R, Carrillo C, Sadeghi N, Nicassio P, Ganz PA, et al. Tai Chi Chih Compared With Cognitive Behavioral Therapy for the Treatment of Insomnia in Survivors of Breast Cancer : A Randomized, Partially Blinded, Noninferiority Trial. J Clin Oncol 2017;35:2656-65.

[78] Jungquist CR, Brien CO, Matteson-rusby S, Smith MT, Pigeon WR, Xia Y, et al. The Efficacy of Cognitive Behavioral Therapy for Insomnia in Patients with Chronic Pain. Sleep Med 2010;11:302-9. doi:10.1016/j.sleep.2009.05.018.The.

[79] Kapella MC, Herdegen JJ, Perlis ML, Shaver JL, Larson JL, Law JA, et al. Cognitive behavioral therapy for insomnia comorbid with COPD is feasible with preliminary evidence of positive sleep and fatigue effects 2011;6:625-35. doi:10.2147/COPD.S24858.

[80] Lancee J, van den Bout J, van Straten A, Spoormaker VI. Internet-delivered or mailed self-help treatment for insomnia? A randomized waiting-list controlled trial. Behav Res Ther 2012;50:22-9. doi:10.1016/j.brat.2011.09.012. 
[81] Lancee J, Eisma MC, van Straten A, Kamphuis JH. Sleep-Related Safety Behaviors and Dysfunctional Beliefs Mediate the Efficacy of Online CBT for Insomnia: A Randomized Controlled Trial. Cogn Behav Ther 2015;44:406-22. doi:10.1080/16506073.2015.1026386.

[82] Lancee J, van Straten A, Morina N, Kaldo V, Kamphuis JH. Guided Online or Face-toFace Cognitive Behavioral Treatment for Insomnia: A Randomized Wait-List Controlled Trial. Sleep 2016;39:183-91. doi:10.5665/sleep.5344.

[83] Lancee J, Yasiney SL, Brendel RS, Boffo M, Patrick J, Clarke F, et al. Attentional bias modification training for insomnia: A double-blind placebo controlled randomized trial 2017.

[84] Lichstein KL, Wilson NM, Johnson CT. Psychological treatment of secondary insomnia. Psychol Aging 2000;15:232-40. doi:10.1037//0882-7974.I5.2.232.

[85] Margolies SO, Rybarczyk B, Vrana SR, Leszczyszyn DJ, Lynch J. Efficacy of a cognitive-behavioral treatment for insomnia and nightmares in afghanistan and iraq veterans with PTSD. J Clin Psychol 2013;69:1026-42. doi:10.1002/jclp.21970.

[86] McCurry SM, Logsdon RG, Vitiello M V, Teri L. Successful behavioral treatment for reported sleep problems in elderly caregivers of dementia patients: A controlled study. Journals Gerontol - Ser B Psychol Sci Soc Sci 1998;53:122-9.

[87] McCurry SM, LaFazia DM, Pike KC, Logsdon RG, Teri L. Development and evaluation of a sleep education program for older adults with dementia living in adult family homes. Am J Geriatr Psychiatry 2012;20:494-504.

[88] Mimeault V, Morin CM. Self-help Treatment for Insomnia: Bibliotherapy With and Without Professional Guidance. J Consult Clin Psychol 1999;67:511-9.

[89] Morin C, Beaulieu-Bonneau S, LeBlanc M, Savard J. Self-help treatment for insomnia: a randomized controlled trial. Sleep 2005;28:1319-27.

[90] Moseley L, Gradisar M. Evaluation of a school-based intervention for adolescent sleep problems. Sleep 2009;32:334-341 8p.

[91] Nguyen S, Mckay A, Wong D, Rajaratnam SM, Spitz G, Williams G, et al. Cognitive Behavior Therapy to Treat Sleep Disturbance and Fatigue After Traumatic Brain Injury : A Pilot Randomized Controlled Trial. Arch Phys Med Rehabil 2017;98:15081517.e2. doi:10.1016/j.apmr.2017.02.031.

[92] Pigeon WR, Moynihan J, Matteson-Rusby S, Jungquist CR, Xia Y, Tu X, et al. Comparative effectiveness of CBT interventions for co-morbid chronic pain \& insomnia: A pilot study. Behav Res Ther 2012;50:685-9. doi:10.1016/j.brat.2012.07.005.

[93] Riedel, Brant W, Lichstein KL, Peterson BA, Epperson MT, Means MK, Aguillard RN. A Comparison of the Efficacy of Stimulus Control for Medicated and Nonmedicated Insomniacs. Behav Modif 1998;22:3-28.

[94] Rios Romenets S, Creti L, Fichten C, Bailes S, Libman E, Pelletier A, et al. Doxepin and cognitive behavioural therapy for insomnia in patients with Parkinson's disease A randomized study. Park Relat Disord 2013;19:670-5. 
doi:10.1016/j.parkreldis.2013.03.003.

[95] Ritterband LM, Bailey ET, Thorndike, Frances P. Lord HR, Farrell-Carnahan, Leah Baum LD. Initial evaluation of an Internet intervention to improve the sleep of cancer survivors with insomnia. Psychooncology 2012;21:695-705.

[96] Savard J, Simard S, Ivers H, Morin CM. Randomized study on the efficacy of cognitive-behavioral therapy for insomnia secondary to breast cancer, part I: Sleep and psychological effects. J Clin Oncol 2005;23:6083-96. doi:10.1200/JCO.2005.09.548.

[97] Savard J, Ivers H, Savard M-H, Morin CM. Is a Video-Based Cognitive Behavioral Therapy for Insomnia as Efficacious as a Professionally Administered Treatment in Breast Cancer? Results of a Randomized Controlled Trial. Sleep 2014;37:1305-14. doi:10.5665/sleep.3918.

[98] Stremler R, Hodnett E, Kenton L, Lee K, Weiss S, Weston J, et al. Effect of behavioural-educational intervention on sleep for primiparous women and their infants in early postpartum: Multisite randomised controlled trial. BMJ 2013;346:1-14. doi:10.1136/bmj.f1164.

[99] Suzuki E, Tsuchiya M, Hirokawa K, Taniguchi T, Mitsuhashi T, Kawakami N. Evaluation of an Internet-Based Self-Help Program for Better Quality of Sleep among Japanese Workers: A Randomized Controlled Trial. J Occup Health 2008;50:387-99.

[100] Swift N, Stewart R, Andiappan M, Smith A, Espie CA, Brown JSL. The effectiveness of community day-long CBT-I workshops for participants with insomnia symptoms: A randomised controlled trial. J Sleep Res 2012;21:270-80. doi:10.1111/j.13652869.2011.00940.x

[101] Talbot LS, Maguen S, Metzler TJ, Schmitz M, McCaslin SE, Richards A, et al. Cognitive Behavioral Therapy for Insomnia in Posttraumatic Stress Disorder: A Randomized Controlled Trial. Sleep 2014;37:327-41. doi:10.5665/sleep.3408.

[102] Tang NKY, Goodchild CE, Salkovskis PM. Hybrid cognitive-behaviour therapy for individuals with insomnia and chronic pain: A pilot randomised controlled trial. Behav Res Ther 2012;50:814-21. doi:10.1016/j.brat.2012.08.006.

[103] Taylor DJ, Zimmerman MR, Gardner CE, Williams JM, Grieser EA, Tatum JI, et al. A pilot randomized controlled trial of the effects of cognitive-behavioral therapy for insomnia on sleep and daytime functioning in college students. Behav Ther 2014;45:376-89. doi:http://dx.doi.org/10.1016/j.beth.2013.12.010.

[104] Thorndike FP, Ritterband LM, Gonder-Frederick LA, Lord HR, Ingersoll KS, Morin CM. A Randomized Controlled Trial of an Internet Intervention for Adults with Insomnia: Effects on Comorbid Psychological and Fatigue Symptoms. J Clin Psychol 2013;69:1078-93. doi:10.1002/jclp.22032.A.

[105] Ulmer CS, Edinger JD, Calhoun PS. A multi-component cognitive-behavioral intervention for sleep disturbance in Veterans with PTSD: A pilot study. J Clin Sleep Med 2011;7:57-68.

[106] van Straten A, Cuijpers P, Smit F, Spermon M, Verbeek I. Self-help treatment for insomnia through television and book: A randomized trial. Patient Educ Couns 
2009;74:29-34. doi:10.1016/j.pec.2008.07.050.

[107] Van Straten A, Emmelkamp J, De Wit J, Lancee J, Andersson G, Van Someren EJW, et al. Guided Internet-delivered cognitive behavioural treatment for insomnia: A randomized trial. Psychol Med 2014;44:1521-32. doi:10.1017/S0033291713002249.

[108] Wagley JN, Rybarczyk B, Nay WT, Danish S, Lund HG. Effectiveness of abbreviated CBT for insomnia in psychiatric outpatients: Sleep and depression outcomes. J Clin Psychol 2013;69:1043-55. doi:10.1002/jclp.21927.

[109] Watanabe N, Furukawa TA, Shimodera S, Morokuma O, Katsuki F, Fujita H, et al. Brief Behavioral Therapy for Refactory Insomnia in Residual Depression: An Assessor-Blind Randomized Controlled Trial. J Clin Psychiatry 2011;72:1651-8. 


\section{Tables}

Table 1. Characteristics of studies included in the meta-analysis

\begin{tabular}{|c|c|c|c|c|c|}
\hline Study & County & Participants & Intervention & $\begin{array}{l}\text { Depression } \\
\text { measure }\end{array}$ & $\begin{array}{l}\text { Sleep } \\
\text { measure }\end{array}$ \\
\hline Blake et al. 2016 [61] & Australia & $\begin{array}{l}\text { Adolescents (aged 12-17) with } \\
\text { high anxiety and sleep difficulties }\end{array}$ & $\begin{array}{l}\text { CBT/mindfulness-based } \\
\text { group sleep intervention }\end{array}$ & CESD & PSQI \\
\hline Casault et al. 2015 [62] & Canada & $\begin{array}{l}\text { Adults diagnosed with cancer } \\
\text { with comorbid insomnia }\end{array}$ & $\begin{array}{l}\text { Self-help CBT-I with } \\
\text { telephone support }\end{array}$ & HADS & ISI \\
\hline Chang et al. 2016 [63] & Taiwan & Adults with heart failure & $\begin{array}{l}\text { Educational supportive care } \\
\text { programme }\end{array}$ & HADS & PSQI \\
\hline Christensen et al. 2016 [64] & Australia & $\begin{array}{l}\text { Adult internet users with insomnia } \\
\text { and subclinical depression }\end{array}$ & $\begin{array}{l}\text { Online insomnia self-help } \\
\text { programme }\end{array}$ & PHQ-9 & ISI \\
\hline Currie et al. 2000 [65] & Canada & $\begin{array}{l}\text { Adults with insomnia secondary } \\
\text { to chronic pain }\end{array}$ & Group CBT-I & BDI & PSQI \\
\hline Currie et al. 2004 [66] & Canada & $\begin{array}{l}\text { Adult recovering alcoholics with } \\
\text { insomnia }\end{array}$ & $\begin{array}{l}\text { Brief CBT-based insomnia } \\
\text { programme }\end{array}$ & BDI & PSQI \\
\hline
\end{tabular}




\begin{tabular}{|c|c|c|c|c|c|}
\hline $\begin{array}{l}\text { Dewald-Kaufmann et al. } \\
2014 \text { [67] }\end{array}$ & Netherlands & $\begin{array}{l}\text { Adolescents (aged 12-19) with } \\
\text { chronic sleep reduction }\end{array}$ & $\begin{array}{l}\text { Gradual sleep extension and } \\
\text { sleep hygiene advice }\end{array}$ & $\overline{\mathrm{CDI}}$ & CSRQ \\
\hline Ebert et al. 2015 [68] & Germany & $\begin{array}{l}\text { Adult teachers with sleeping } \\
\text { problems }\end{array}$ & $\begin{array}{l}\text { Online CBT-I based recovery } \\
\text { training programme }\end{array}$ & CESD & PSQI \\
\hline Edinger et al. 2001 [69] & USA & $\begin{array}{l}\text { Adults with chronic primary } \\
\text { sleep-maintenance insomnia }\end{array}$ & Individual CBT-I & BDI & ISQ \\
\hline Edinger et al. 2007 [70] & USA & $\begin{array}{l}\text { Adults with primary-sleep- } \\
\text { maintenance insomnia }\end{array}$ & Individual CBT-I & BDI & ISQ \\
\hline Freeman et al. 2017 [71] & UK & $\begin{array}{l}\text { Adult university students with } \\
\text { insomnia }\end{array}$ & $\begin{array}{l}\text { Online CBT-I delivered via a } \\
\text { media-rich web application }\end{array}$ & PHQ-9 & ISI \\
\hline Galovski et al. 2016 [72] & USA & $\begin{array}{l}\text { Adult female interpersonal assault } \\
\text { survivors with sleep impairment }\end{array}$ & Sleep-directed hypnosis & BDI-II & PSQI \\
\hline Gradisar et al. 2011 [73] & Australia & $\begin{array}{l}\text { Adolescents (aged 11-18) } \\
\text { diagnosed with delayed sleep } \\
\text { phase disorder }\end{array}$ & $\begin{array}{l}\text { Individual CBT plus morning } \\
\text { bright light }\end{array}$ & MFQ & None \\
\hline Ho et al. 2014 [74] & China & Adult internet users with insomnia & Online self-help CBT-I with & HADS & PSQI \\
\hline
\end{tabular}




\begin{tabular}{|c|c|c|c|c|c|}
\hline & & & telephone support & & \\
\hline Horsch et al. 2017 [75] & Netherlands & $\begin{array}{l}\text { Adult with insomnia and an } \\
\text { Android mobile phone }\end{array}$ & $\begin{array}{l}\text { CBT-I delivered via an } \\
\text { automated mobile phone app }\end{array}$ & CESD & PSQI \\
\hline Hou et al. 2014 [76] & China & $\begin{array}{l}\text { Adults with end stage renal } \\
\text { disease and comorbid insomnia }\end{array}$ & Individual CBT-I & SCL-90 & PSQI \\
\hline Irwin et al. 2017 [77] & USA & $\begin{array}{l}\text { Adult survivors of breast cancer } \\
\text { with insomnia }\end{array}$ & Group CBT-I & IDS-C & PSQI \\
\hline Jungquist et al. 2010 [78] & UK & $\begin{array}{l}\text { Adults with insomnia comorbid } \\
\text { with chronic pain }\end{array}$ & Individual CBT-I & BDI & ISI \\
\hline Kapella et al. 2011 [79] & USA & $\begin{array}{l}\text { Adults with insomnia and chronic } \\
\text { obstructive pulmonary disease }\end{array}$ & Individual CBT-I & POMS-D & PSQI \\
\hline Lancee et al. 2012 [80] & Netherlands & Adult internet users with insomnia & Online self-help CBT-I & CESD & SLEEP-50 \\
\hline Lancee et al. 2015 [81] & Netherlands & Adult internet users with insomnia & Online self-help CBT-I & CESD & ISI \\
\hline Lancee et al. 2016 [82] & Netherlands & Adult internet users with insomnia & Online guided CBT-I & CESD & ISI \\
\hline
\end{tabular}




\begin{tabular}{|c|c|c|c|c|c|}
\hline Lancee et al. 2017 [83] & Netherlands & Adult internet users with insomnia & $\begin{array}{l}\text { Attentional bias modification } \\
\text { training }\end{array}$ & CESD & ISI \\
\hline Lichstein et al. 2000 [84] & USA & $\begin{array}{l}\text { Older adults (aged 58+) with } \\
\text { insomnia secondary to illness }\end{array}$ & $\begin{array}{l}\text { Sleep hygiene, stimulus control } \\
\text { and relaxation }\end{array}$ & GDS & None \\
\hline Margolies et al. 2013 [85] & USA & $\begin{array}{l}\text { Adult veterans with PTSD and } \\
\text { sleep disturbance }\end{array}$ & $\begin{array}{l}\text { CBT-I combined with imagery } \\
\text { rehearsal therapy }\end{array}$ & PHQ-9 & PSQI \\
\hline McCurry et al. 1998 [86] & USA & $\begin{array}{l}\text { Older adult (aged 50+) dementia } \\
\text { caregivers with sleep problems }\end{array}$ & $\begin{array}{l}\text { Group educational and } \\
\text { behavioural intervention }\end{array}$ & CESD & PSQI \\
\hline McCurry et al. 2012 [87] & USA & $\begin{array}{l}\text { Older adults with dementia } \\
\text { resident in small care homes }\end{array}$ & Sleep education for care-staff & CSDD & None \\
\hline $\begin{array}{l}\text { Mimeault \& Morin } 1999 \\
\text { [88] }\end{array}$ & Canada & Adults with primary-insomnia & $\begin{array}{l}\text { Self-help CBT-I with } \\
\text { telephone support }\end{array}$ & BDI & PSQI \\
\hline Morin et al. 2005 [89] & Canada & Adults with insomnia symptoms & Self-help CBT-I & BDI-II & PSQI \\
\hline Moseley et al. 2009 [90] & Australia & Adolescent high school students & CBT-I-based classroom sleep & DASS-21 & None \\
\hline
\end{tabular}




\begin{tabular}{|c|c|c|c|c|c|}
\hline & & (aged 15/16) & education programme & & \\
\hline Nguyen et al. 2017 [91] & Australia & $\begin{array}{l}\text { Adults with traumatic brain injury } \\
\text { and sleep/fatigue complaints }\end{array}$ & $\begin{array}{l}\text { Individual CBT-I adapted for } \\
\text { traumatic brain injury }\end{array}$ & HADS & PSQI \\
\hline Pigeon et al. 2012 [92] & USA & $\begin{array}{l}\text { Adults with co-occurring chronic } \\
\text { pain and chronic insomnia }\end{array}$ & CBT for insomnia and pain & CESD & ISI \\
\hline Riedel et al. 1998 [93] & USA & Adults with insomnia & $\begin{array}{l}\text { Individual stimulus control } \\
\text { sessions }\end{array}$ & BDI & None \\
\hline $\begin{array}{l}\text { Rios Romenets et al. } 2013 \\
\text { [94] }\end{array}$ & Canada & $\begin{array}{l}\text { Adults with Parkinson's disease } \\
\text { and insomnia }\end{array}$ & $\begin{array}{l}\text { Sleep hygiene training, CBT-I } \\
\text { and bright light therapy }\end{array}$ & BDI & ISI \\
\hline Ritterband et al. 2012 [95] & USA & $\begin{array}{l}\text { Adult internet users in remission } \\
\text { from cancer with secondary } \\
\text { insomnia }\end{array}$ & Online CBT-I & HADS & ISI \\
\hline Savard et al. 2005 [96] & Canada & $\begin{array}{l}\text { Adult women with insomnia } \\
\text { secondary to breast cancer }\end{array}$ & Group CBT-I & HADS & ISI \\
\hline Savard et al. 2014 [97] & Canada & $\begin{array}{l}\text { Adult women with breast cancer } \\
\text { and insomnia symptoms who }\end{array}$ & Individual CBT-I & HADS & ISI \\
\hline
\end{tabular}




\begin{tabular}{|c|c|c|c|c|c|}
\hline & & received radiation therapy & & & \\
\hline Stremler et al. 2013 [98] & Canada & $\begin{array}{l}\text { Adult women who had recently } \\
\text { given birth for the first time }\end{array}$ & Sleep education and advice & EPDS & GSDS \\
\hline Suzuki et al. 2008 [99] & Japan & $\begin{array}{l}\text { Adult workers with a desire to } \\
\text { improve their sleep quality }\end{array}$ & $\begin{array}{l}\text { Online CBT-based self-help } \\
\text { programme }\end{array}$ & K6 & PSQI \\
\hline Swift et al. 2012 [100] & UK & $\begin{array}{l}\text { Adults who responded to a flyer } \\
\text { advertising sleep workshops }\end{array}$ & One-day CBT-I workshop & BDI & ISI \\
\hline Talbot et al. 2014 [101] & USA & Adults with PTSD and insomnia & Individual CBT-I & BDI & ISI \\
\hline Tang et al. 2012 [102] & UK & $\begin{array}{l}\text { Adults with chronic pain and } \\
\text { insomnia }\end{array}$ & $\begin{array}{l}\text { Individual hybrid CBT for } \\
\text { insomnia and chronic pain }\end{array}$ & HADS & ISI \\
\hline Taylor et al. 2014 [103] & USA & $\begin{array}{l}\text { Adult college students with } \\
\text { insomnia }\end{array}$ & Individual CBT-I & QIDS & PSQI \\
\hline Thorndike et al. 2013 [104] & USA & Adult internet users with insomnia & Online self-help CBT-I & BDI-II & ISI \\
\hline
\end{tabular}




\begin{tabular}{|c|c|c|c|c|c|}
\hline Ulmer et al. 2011 [105] & USA & $\begin{array}{l}\text { Adult veterans meeting criteria for } \\
\text { PTSD and insomnia }\end{array}$ & $\begin{array}{l}\text { Sleep intervention for PTSD } \\
\text { (CBT and imagery rehearsal } \\
\text { therapy) }\end{array}$ & PHQ-2 & PSQI \\
\hline $\begin{array}{l}\text { van Straten et al. } 2009 \\
\text { [106] }\end{array}$ & Netherlands & Adults with insomnia symptoms & $\begin{array}{l}\text { Self-help CBT-I delivered via a } \\
\text { book and television }\end{array}$ & CESD & SEF \\
\hline $\begin{array}{l}\text { van Straten et al. } 2014 \\
\text { [107] }\end{array}$ & Netherlands & Adults with insomnia & $\begin{array}{l}\text { Online CBT-I with support of } \\
\text { online coach }\end{array}$ & CESD & PSQI \\
\hline Wagley et al. 2013 [108] & USA & $\begin{array}{l}\text { Adult psychiatric outpatients with } \\
\text { low sleep quality and depression } \\
\text { symptoms }\end{array}$ & Two session individual CBT-I & PHQ-9 & PSQI \\
\hline Watanabe et al. 2011 [109] & Japan & $\begin{array}{l}\text { Adult psychiatric outpatients with } \\
\text { depression and insomnia }\end{array}$ & Individual CBT-I & HDRS & PSQI \\
\hline
\end{tabular}

Abbreviations. BDI = Beck depression inventory; CBT-I = cognitive behavioural therapy for insomnia; CDI = children's depression inventory;

$\mathrm{CESD}=$ centre for epidemiological studies depression scale; CSDD = Cornell Scale for Depression in Dementia; CSRQ = chronic sleep

reduction questionnaire; DASS = depression anxiety stress scale; GDS = geriatric depression scale; GSDS = general sleep disturbance scale;

HADS = hospital anxiety and depression scale (depression subscale); HDRS = Hamilton depression rating scale; ISI = insomnia severity index; 
K6 $=$ Kessler psychological distress scale $; \mathrm{MFQ}=\operatorname{mood}$ and feeling questionnaire $; \mathrm{PHQ}=$ patient health questionnaire $; \mathrm{POMS}-\mathrm{D}=$ profile of mood states depression subscale; PSQI = Pittsburgh sleep quality inventory; SCI = sleep condition indicator; SCL-90 = symptom checklist 


\section{Figure Legends}

Figure 1. Flow diagram of study selection process

Figure 2. Risk of bias graph

Figure 3. Forrest plot for meta-analysis of the effect of non-pharmacological sleep interventions on depression symptoms. 